\title{
Performance Evaluation of Hinges in Long-Span Cantilever Steel Truss Bridges by Structural Health Monitoring
}

\author{
Takeshi Miyashita, Eiji Iwasaki, and Masatsugu Nagai \\ Nagaoka University of Technology, 1603-1 Kamitomioka, Nagaoka, Niigata 940-2188, Japan
}

(Received June 20, 2016; accepted December 1, 2016)

Keywords: structural health monitoring, steel truss bridges, strain, temperature

In this study, short-term monitoring was carried out for an existing long-span bridge, which has been managed by a local government, with the aim of evaluating its present performance toward planning future maintenance strategies. The bridge studied is a cantilever steel truss bridge, which was completed and opened to traffic in 1937. Consequently, the performance of Gerber hinges was evaluated, then information on repair was obtained.

\section{Introduction}

Owing to the aging of bridges in Japan, effective and efficient maintenance has been demanded.(1) Until now, visual inspection is the most effective maintenance method. However, work optimization for this type of inspection is difficult, and quantitative information about stress properties, which is necessary for effective maintenance, cannot be obtained. On the other hand, aiming at efficient maintenance, it is considered that the use of ICRT (ICT: Information and Communication Technology + IRT: Information and Robot Technology) technologies will continue to increase in the near future. ${ }^{(2)}$

One example related with the initiative for the use of ICRT technologies is bridge monitoring, which involves a large number of sensors installed along the bridge in order to monitor its condition and diagnose its soundness. ${ }^{(3)}$ One of the problems that have arisen is that there are only a few applications of both types of inspection in long-span bridges administrated by local governments.

Of course, cost represents a major issue for its application, but this is not the only obstacle. There is also the technical difficulty of arranging sensors throughout the entire bridge, constructing a measurement system, and analyzing a large amount of data. Notwithstanding these difficulties, since July of 2014, bridge inspection every 5 years has become mandatory in Japan. Henceforth, it is expected that the demands for methods of evaluating current conditions and methods of bridge monitoring will continue to increase.

In this research, aiming at the establishment of a strategy for the future maintenance of longspan bridges administrated by local governments, a short-term monitoring is carried out. More than one hundred sensors are installed along the bridge in order to evaluate its current performance. Herein, strain responses, which are affected by temperature, are focused on in order to evaluate the performance of hinges.

"Corresponding author: e-mail: mtakeshi@vos.nagaokaut.ac.jp http://dx.doi.org/10.18494/SAM.2017.1419 


\section{Bridge of Study}

The bridge of study is Chosei Bridge, an 850.8-m-long bridge built over Shinano River, located in Niigata Prefecture. It is a 13-span (67.50+11@65.00+67.50 m) cantilever (Gerber) steel truss bridge completed and opened to traffic in 1937 (Fig. 1). The road width corresponding to this bridge is $7.50 \mathrm{~m}$. The pedestrian bridge adjacent to Chosei Bridge was constructed in 1972 .

From 1995 to 1996, movable supports and a bridge fail-safe system corresponding to a Gerber hinge section were replaced and installed, respectively. In 2003, construction works to implement nondrain expansion devices in all Gerber hinges were carried out. Figure 2 shows the current condition of the Gerber hinges.

In 2006, during the repainting of the 2nd span, considerable corrosion in the lower chords of the main structure was found, and it was determined that it was necessary to repair those damaged sections. On the basis of the corrosion condition examination performed that year, a repair design was drawn up. Then, from 2007 to 2011, the lower chords were repaired (patching of steel plates and member replacements). However, no loading test was performed after the repair, so the stress state and other current properties of the bridge were not determined.

\section{Short-Term Monitoring}

\subsection{Outline}

The measured items are the strain of each span, acceleration, vertical deflection, and temperature in the span center vicinity as a representative point. Additionally, since the adjacent pedestrian bridge shares the same pier with Chosei Bridge, for reference, acceleration measurements of 3 spans corresponding to the pedestrian bridge were carried out. In total, 130 points were measured. The measurement location is shown in Fig. 3. To classify vehicle type, a previously installed web camera, originally used for monitoring snow conditions, was used. However, in this paper, strain responses, which are affected by temperature, are focused on among the sensors.

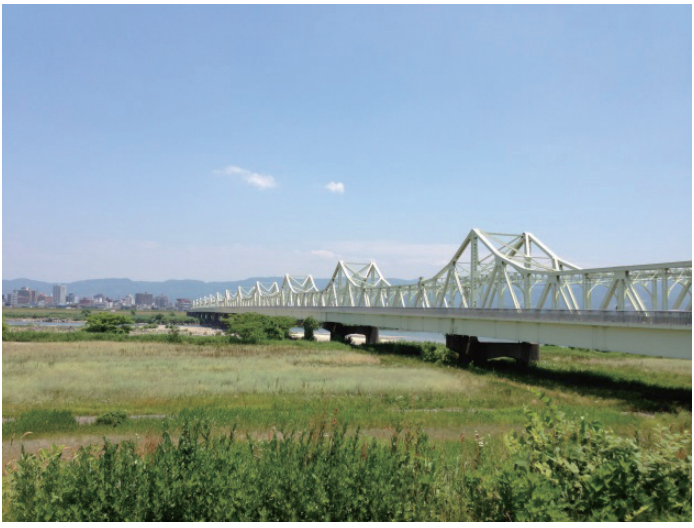

Fig. 1. (Color online) Bridge of study (Chosei Bridge).

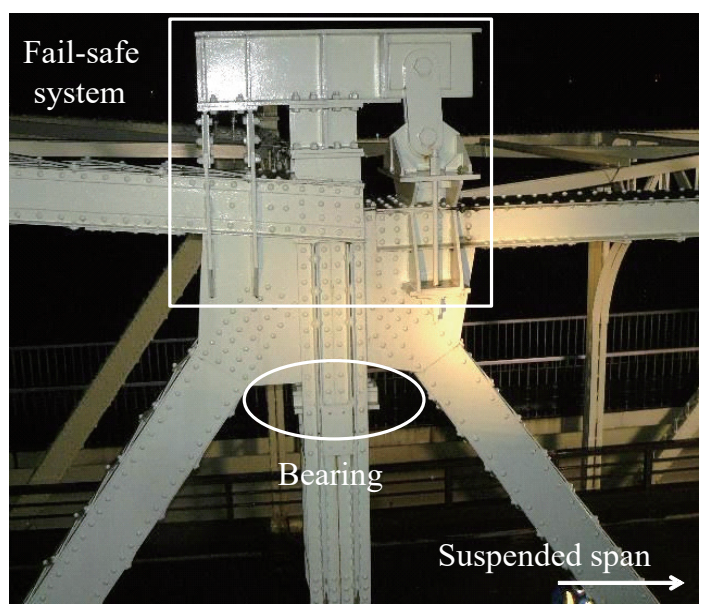

Fig. 2. (Color online) Current condition of Gerber hinges. 


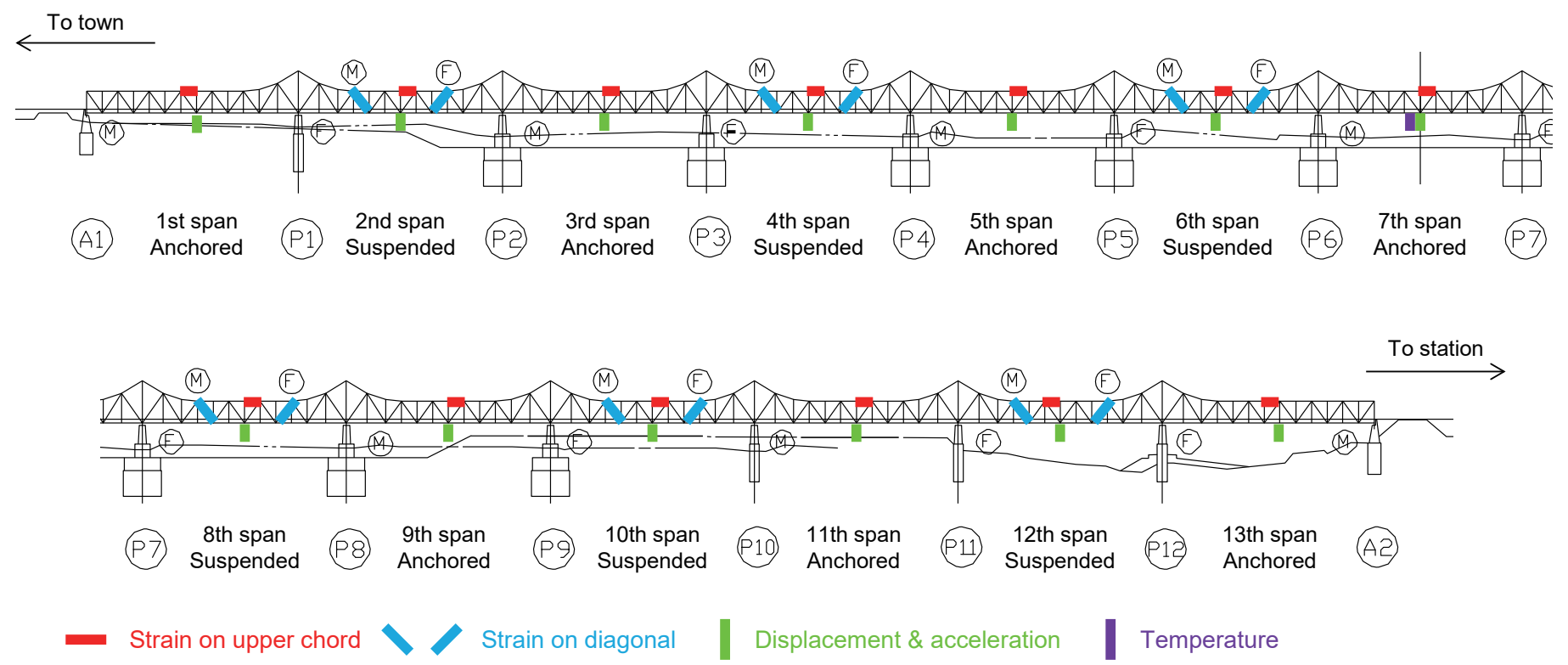

Fig. 3. (Color online) Measurement location.

Free-flow traffic monitoring was carried out, starting at 2:00 of June 13 and ending at 14:00 of June 17, 2013, with a total of $108 \mathrm{~h}(388800 \mathrm{~s})$ of monitoring. The sampling frequency was 200 Hz. After completing the measurements, all the measurement systems were removed. For the monitoring period, a file text of approximately $18.8 \mathrm{~GB}$ was obtained. In this research, attention was focused on strain data that helps to determine stress properties.

Since the bridge of study is quite long $(850.8 \mathrm{~m})$, it was difficult to gather together all the sensors' wirings in the same place. It was also difficult to close the road to traffic for long periods of time, so the bridge was divided into 3 blocks, and a measurement system was constructed for each block (Tokyo Sokki Kenkyujyo TMR-211 and 221). All sensors were connected by wires, and the order of measurements, such as starting and ending, were transmitted to each block via wireless signal.

\subsection{Strain measurement}

To measure the strain, self-temperature compensation-type uniaxial strain gauges for general use (Tokyo Sokki Kenkyujyo) were employed. Strain was measured in the upper chord located in the vicinity of each span's center on the downstream side. Additionally, in the cantilever span, measurement points were provided at the 2 diagonal bracing members that connect from the Gerber hinge to the span center. In order to consider the effect of axial force and bending moments, 4 strain gauges were attached at each cross section of each element. To calculate the section force from the measured strain, members' coordinate systems shown in Fig. 4, Young's modulus $E$ of steel $(=200$ GPa), cross-sectional area $A$, cross-sectional coefficients $W_{y i}$ and $W_{z i}(i=1,2,3,4)$, axial force $N_{x}$, bending moments around $y$ - and $z$-axes $M_{y}$ and $M_{z}$, measured strain $\varepsilon_{i}$, and the following formula were used. $N_{x}, M_{y}$, and $M_{z}$ are obtained by the least squares method. 


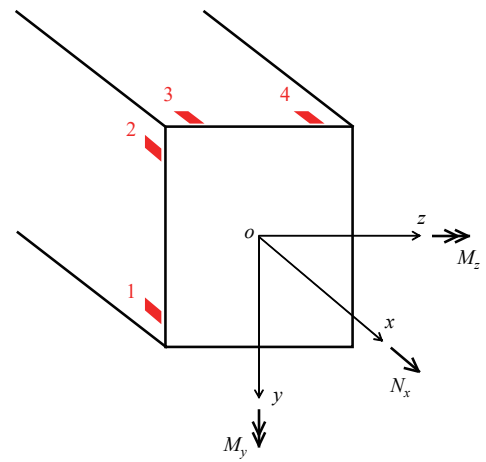

Fig. 4. (Color online) Coordinate system of members.

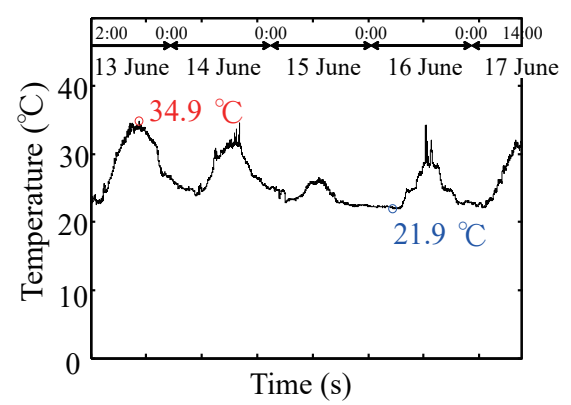

Fig. 5. (Color online) Temperature during monitoring period.

$$
\frac{1}{E}\left[\begin{array}{ccc}
1 / A & 1 / W_{z 1} & 1 / W_{y 1} \\
1 / A & 1 / W_{z 2} & 1 / W_{y 2} \\
1 / A & 1 / W_{z 3} & 1 / W_{y 3} \\
1 / A & 1 / W_{z 4} & 1 / W_{y 4}
\end{array}\right]\left[\begin{array}{c}
N_{x} \\
M_{z} \\
M_{y}
\end{array}\right]=\left[\begin{array}{c}
\varepsilon_{1} \\
\varepsilon_{2} \\
\varepsilon_{3} \\
\varepsilon_{4}
\end{array}\right]
$$

\subsection{Temperature measurement and web camera}

The vicinity of the 7th span's center was selected as the representative point to measure the temperature. The temperature measurement was carried out using the thermocouple T-GF-0.65 (Tokyo Sokki Kenkyujyo), which uses the Seebeck effect. It was installed above the pedestrian bridge, in a position not reached by the sun. In order to classify vehicle type, a previously installed web camera (Panasonic BB-HCM381), originally used to monitor snow conditions, was used. It was installed above the upper lateral bracing located in the vicinity of P1 in the 2nd span.

\section{Monitoring Results}

\subsection{Temperature measurement}

Temperature variation corresponding to the vicinity of the 7th span's center, measured with the installed thermocouple, is shown in Fig. 5. During the measurement period, the maximum temperature was $34.9^{\circ} \mathrm{C}$, and the minimum temperature was $21.9^{\circ} \mathrm{C}$. The temperature when the initial measurement was carried out, on May 22, 2013, was $21^{\circ} \mathrm{C}$.

\subsection{Strain measurement}

Figure 6 shows the upper chord's normal stress for each span. The black solid line represents the normal stress, which is the sum of the static stress component caused by temperature variation, and the dynamic stress component caused by the live load. To separate the two components, a moving average is carried out. Here, 20000 data items for each time are considered. From this moving average, the static stress component is determined and represented by the blue solid line. Then, the blue solid line's value is subtracted from the black solid line's value in order to obtain the dynamic stress component. 

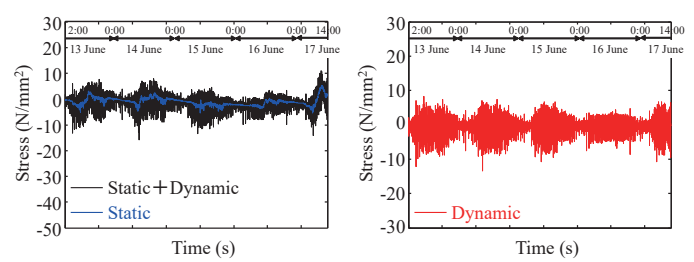

(a)

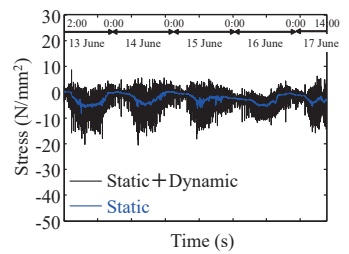

(c)
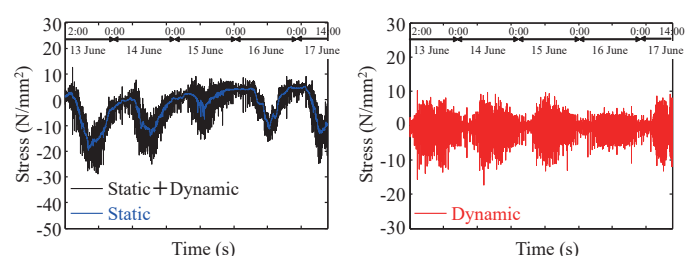

(e)
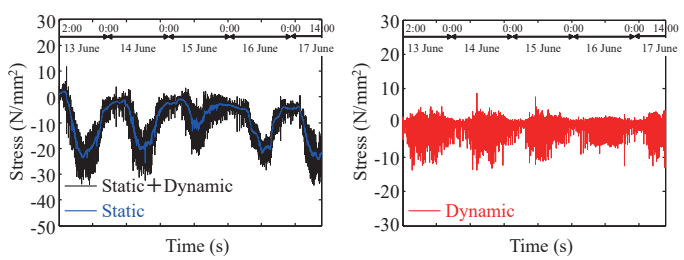

(g)
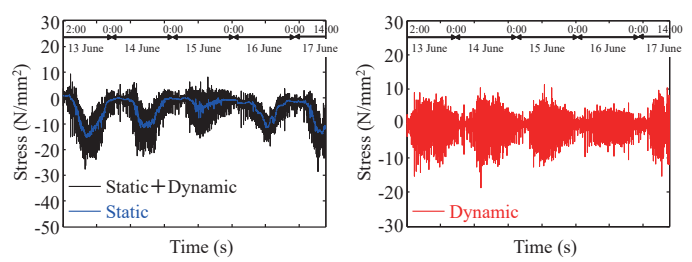

(i)
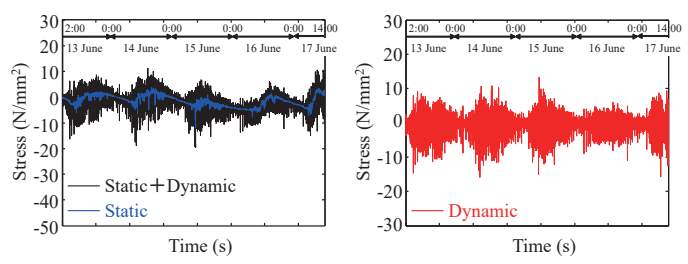

(k)
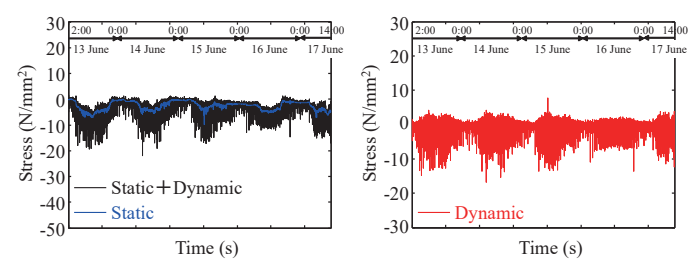

(b)
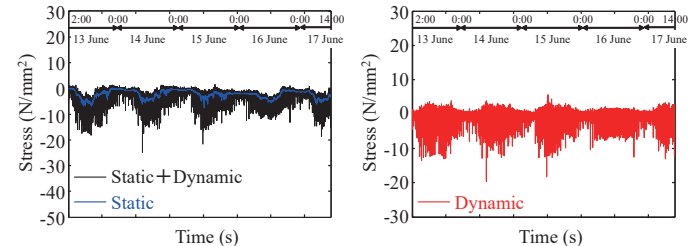

(d)
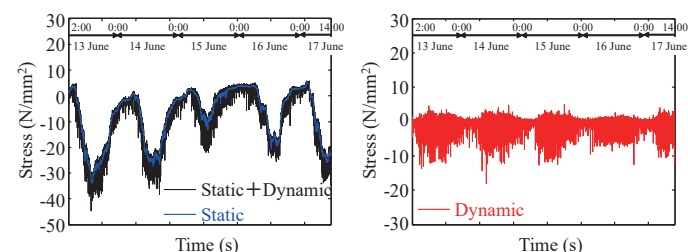

(f)
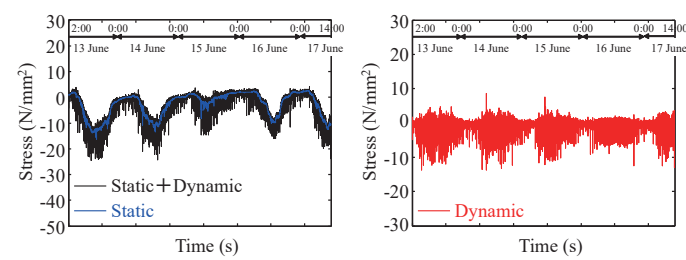

(h)
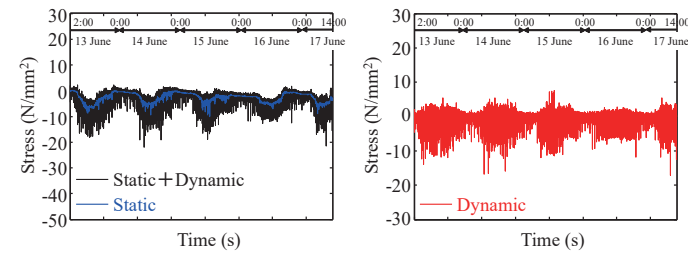

(j)
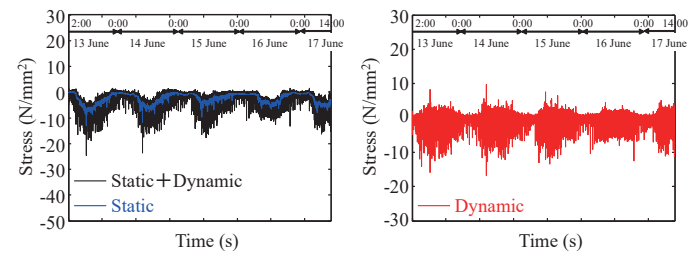

(1)
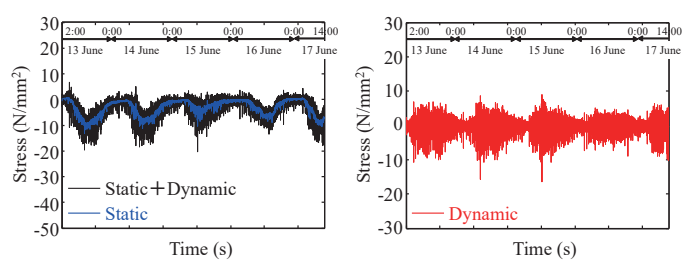

(m)

Fig. 6. (Color online) Upper chord's normal stress for each span. (a) 1st, (b) 2nd, (c) 3rd, (d) 4th, (e) 5th, (f) 6th, (g) 7th, (h) 8th, (i) 9th, (j) 10th, (k) 11th, (l) 12th, and (m) 13th spans. 
Table 1 shows each component of the minimum normal stress for each span during the monitoring period. As shown in Table 1, the 6th span is the span that presented the minimum normal stress, which is $-44.6 \mathrm{MPa}$. An analysis of the data corresponding to this stress and vehicle identification using the web camera are shown in Fig. 7. From Fig. 7(c), it is determined that the dynamic stress component when the normal stress reached its minimum is $-11.6 \mathrm{MPa}$.

As shown in Table 1, the dynamic stress component on the 4th span is $-19.7 \mathrm{MPa}$. An analysis of the data corresponding to this stress and vehicle identification using the web camera are shown in Fig. 8.

Then, from Table 1, it is found that the dynamic stress component on the 6th span is -33.7 MPa. Now, using the temperature variation during the period of monitoring $(34.9-21.9=13.0$ $\left.{ }^{\circ} \mathrm{C}\right)$, the steel coefficient of linear expansion $\left(12 \times 10^{-6} / \mathrm{deg}\right)$, and Young's coefficient of steel (200 $\mathrm{GPa}$ ), the temperature stress is calculated. Its value is $-31.2 \mathrm{MPa}$. Because this stress is of the same magnitude as that of the static stress component presented in the 6th span, it is inferred that the Gerber hinge movable part is not working, and that it is fixed. Considering this, the relationship between temperature and the static stress component is shown in Fig. 9. In 5th, 6th, and 8th spans, the coefficient of determination $R^{2}$ of 0.9 is exceeded. Among these 3 spans, the 6th and 8th spans are cantilever spans, and a high correlation between temperature and the static stress component corresponding to the upper chord of both spans is found. Therefore, it is considered that the Gerber hinges of these spans should be repaired preferentially.

Table 1

Minimum normal stress during the monitoring period.

\begin{tabular}{|c|c|c|c|c|c|c|c|c|c|c|c|c|c|}
\hline pan & 1 & 2 & 3 & 4 & 5 & 6 & 7 & 8 & 9 & 10 & 11 & 12 & 13 \\
\hline Static + dy & -15.8 & -21.9 & -20.5 & -24.8 & -28.8 & -44.6 & -34.1 & -24.4 & -28.5 & -21.9 & -19.6 & -24.6 & -20.4 \\
\hline tatic & -5.4 & -9.8 & -8.2 & -7.4 & -19.5 & -33.7 & -25.5 & -16.3 & -15.4 & -10.1 & -11.8 & -13.0 & -13.2 \\
\hline Dynamic & -13.3 & -16.9 & -16.5 & -19.7 & -17.3 & -18.0 & -17.7 & -13.8 & -18.8 & -17.1 & -16.0 & -16.7 & -16.3 \\
\hline
\end{tabular}

Unit: $\mathrm{N} / \mathrm{mm}^{2}$

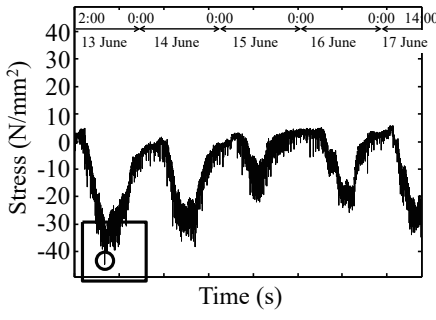

(a)

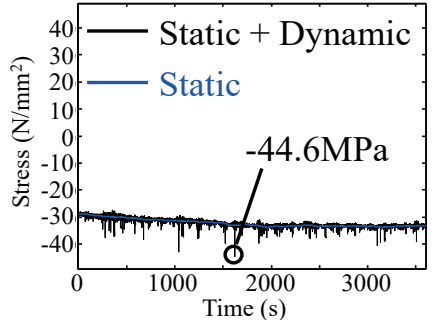

(b)

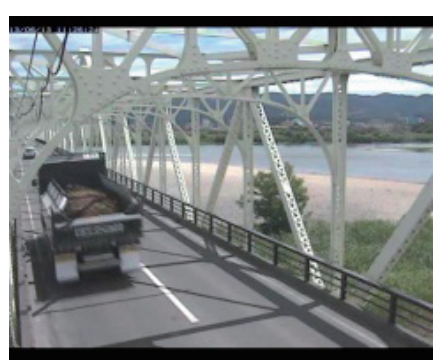

(d)

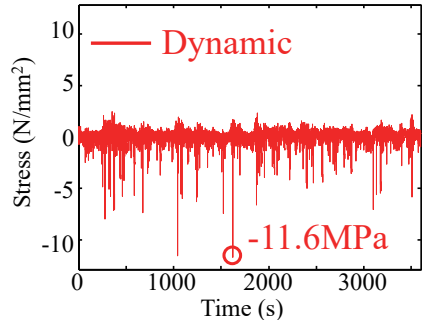

(c)

figure. (b) Static component in square. (c) Dynamic component in square. (d) Identified vehicle. 


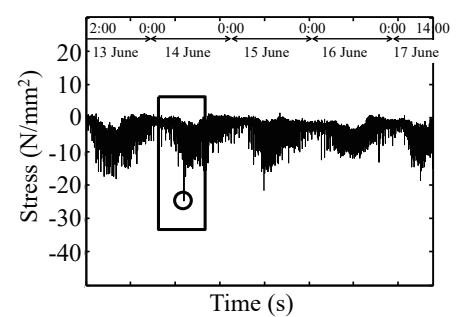

(a)

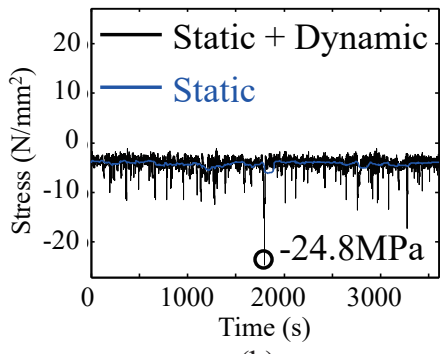

(b)

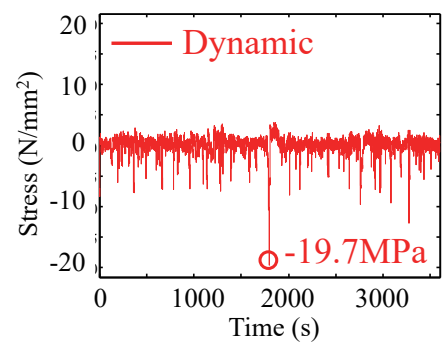

(c)

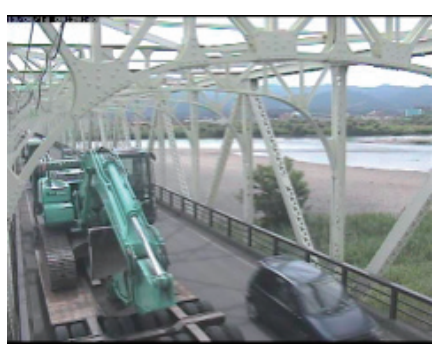

(d)

Fig. 8. (Color online) Minimum dynamic normal stress during monitoring period (upper chord in 4th span). (a) Whole figure. (b) Static component in square. (c) Dynamic component in square. (d) Identified vehicle.

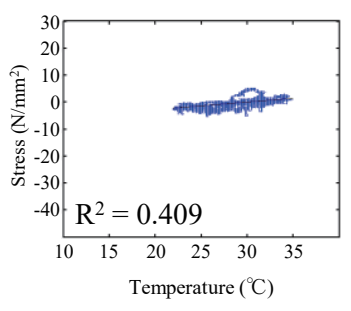

(a)

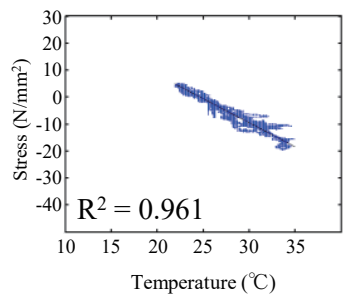

(e)

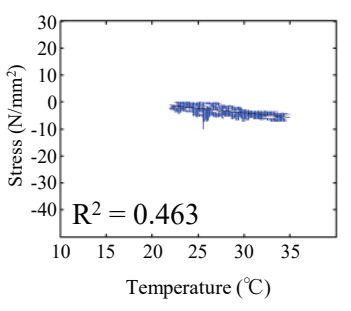

(b)

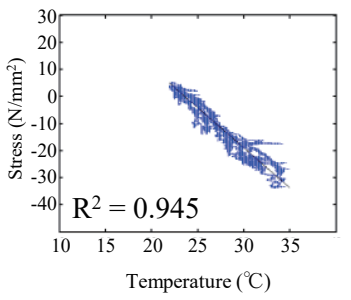

(f)

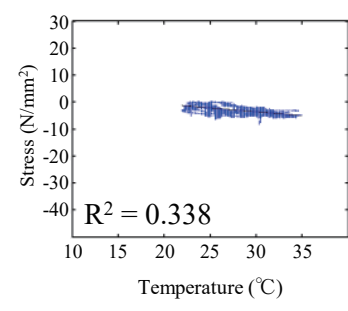

(c)

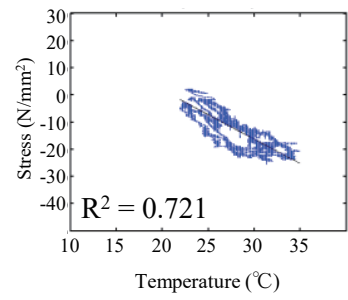

(g)

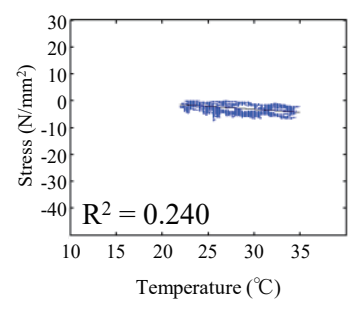

(d)

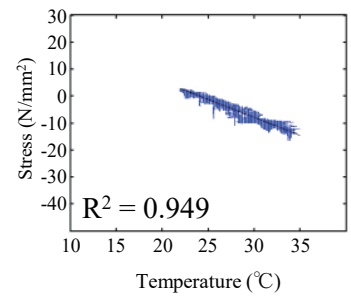

(h)

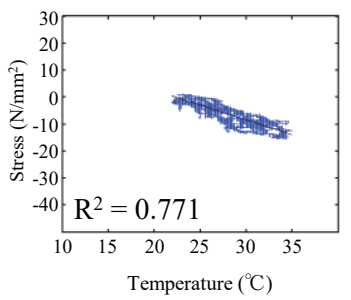

(i)

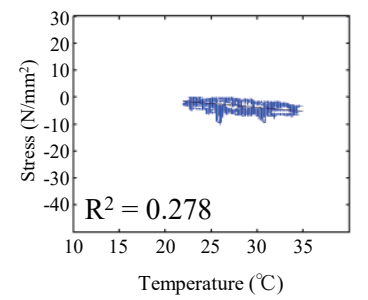

(j)

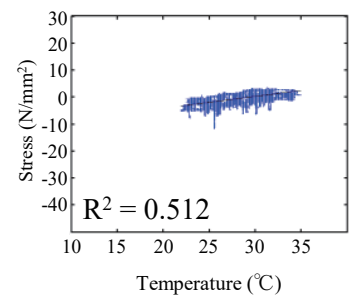

(k)

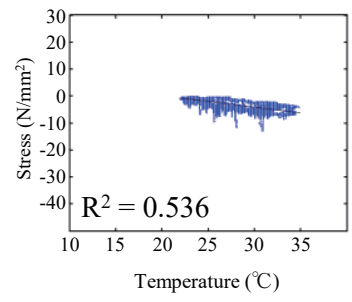

(1)

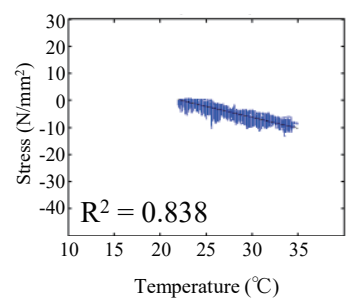

(m)

Fig. 9. (Color online) Relationship between temperature and the static stress component. (a) 1st, (b) 2nd, (c) 3rd, (d) 4th, (e) 5th, (f) 6th, (g) 7th, (h) 8th, (i) 9th, (j) 10th, (k) 11th, (l) 12th, and (m) 13th spans. 


\section{Conclusions}

In this research, aiming at the establishment of strategies for the future maintenance of long-span bridges administrated by local governments, a short-term monitoring was carried out. Here, more than one hundred sensors were installed along a bridge in order to evaluate its current performance. Herein, strain responses, which are affected by temperature, are focused on.

Results after $4.5 \mathrm{~d}$ of monitoring showed that, in the case of the upper chord's normal stress, the static stress component fluctuation is larger than the dynamic stress component fluctuation. The minimum static stress component was found to be of the same magnitude as that of the temperature stress. Therefore, it was inferred that the Gerber hinge movable part was not working, and that it was fixed. Additionally, on the basis of the relationship between each span temperature and the static stress component, a high correlation between temperature and the static stress component corresponding to the upper chord of the 6th and 8th spans was found. It is considered that the Gerber hinges of these spans should be repaired preferentially.

\section{References}

1 M. Nagai and T. Miyashita: Recent Topics on Steel Bridge Engineering in Japan—Design and Maintenance, Proc. 10th Korea-China-Japan Symp. Steel Structures (CD-ROM).

2 Cross-Ministerial Strategic Innovation Promotion Program: Homepage of Cross-Ministerial Strategic Innovation Promotion Program, http://www.jst.go.jp/sip/k07.html (accessed June 2016).

3 C. Boller, F. K. Chang, and Y. Fujino: Encyclopedia of Structural Health Monitoring (Wiley, New Jersey, 2009).

\section{About the Authors}

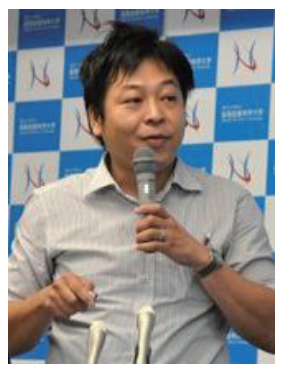

Takeshi Miyashita received his B.S., M.S., and Ph.D. degrees from the University of Tokyo, Japan, in 2001, 2002, and 2005, respectively. From 2006 to 2008, he was an assistant professor at Nagaoka University of Technology, Japan. From 2008 to 2012, he was an especially appointed lecturer at Nagaoka University of Technology. Since 2012, he has been an associate professor at Nagaoka University of Technology. His research interests are in bridge engineering, structural health monitoring, and CFRP repair.

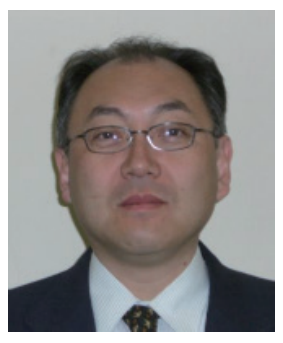

Eiji Iwasaki received his B.S., M.S., and Ph.D. degrees from Nagaoka University of Technology, Japan, in 1985, 1987, and 1990, respectively. From 1990 to 1998, he was an assistant professor at Nagaoka University of Technology, Japan. From 1998 to 2000, he was an associate professor at National Institute of Technology, Tokuyama College, Japan. From 2000 to 2012, he was an associate professor at Nagaoka University of Technology. Since 2012, he has been a professor at Nagaoka University of Technology. His research interests are in structural analysis and weathering steel bridges.

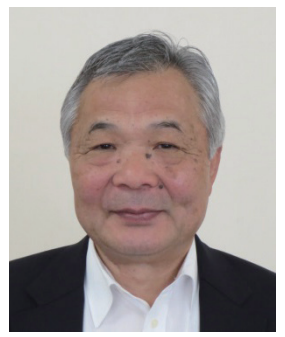

Masatsugu Nagai received his B.S., M.S., and Ph.D. degrees from Osaka University, Japan, in 1971, 1973, and 1982, respectively. From 1973 to 1988, he belonged to the bridge design department of Kawasaki Heavy Industries, Ltd. From 1988 to 1996, he was an associate professor at Nagaoka University of Technology. From 1996 to 2013, he was a professor at Nagaoka University of Technology. Since 2013, he has been a professor emeritus at Nagaoka University of Technology. His main field is cable-supported bridges and hybrid structures. 